\title{
ЭКСПЕРТИЗА ВРЕМЕННОЙ НЕТРУДОСПОСОБНОСТИ В СССР И ПОСТСОВЕТСКОЙ РОССИИ: ВРАЧИ НА СЛУЖБЕ ГОСУДАРСТВА В УПРАВЛЕНИИ ТРУДОВЫМИ РЕСУРСАМИ
}

\begin{abstract}
В статье в сравнительно-историческом ключе рассматриваются советская модель и современная организация экспертизы временной нетрудоспособности - одного из самых массовых видов экспертиз, используемых для целей государственного управления в России. В центре внимания три составляющие экспертизы: идеология или господствующее понимание ее задач; особенности организации и регламентации процедур; практики экспертной деятельности. Ключевой вопрос - претерпел ли изменения сложившийся в советское время институт на фоне кардинального изменения отношения государства к труду и занятости. Автор опирается на сравнительный анализ нормативных актов СССР и РФ, регулирующих данную сферу, и содержания советской и современной учебно-методической литературы для врачей. Для определения того, как выписка больничных листков была организована на практике в советское время, использованы архивные материалы ВЦСПС за 1930 - 1980 гг. Оценка современных практик экспертизы основана на материалах 31 полуструктурированного интервью с практикующими врачами, а также с представителями руководства медицинских организаций и контрольных инстанций. Показано, что институт экспертизы временной нетрудоспособности в советское время сложился в первую очередь как инструмент рационального распределения трудовых ресурсов в зависимости от состояния здоровья. В таком виде с задачей экспертизы медицинские учреждения не справлялись, воспринимая ее процедуры и правила формально. Тем не менее процедуры и правила влияли и продолжают влиять на организацию профессиональной врачебной деятельности и лечебного
\end{abstract}

Юлия Александровна Крашенинникова - к. и. н., эксперт лаборатории муниципального управления НИУ ВШЭ, Москва, доцент, факультет экономики, менеджмента и бизнесинформатики, Пермь, Россия. Электронная почта: jkrasheninnikova@hse.ru 
процесса, определяя рутину взаимодействия медицинской организации с пациентом.

Ключевые слова: экспертиза временной нетрудоспособности, советское здравоохранение, врачебная комиссия, врачебно-трудовая экспертиза, государственное социальное страхование, больничный лист

DOI: 10.17323/727-0634-2017-15-4-531-546

\section{Введение}

Экспертная деятельность врача предполагает оценку здоровья человека, необходимую для решения немедицинских вопросов и имеющую правовые последствия. Среди шести видов медицинских экспертиз, установленных российским законодательством, некоторые закреплены за особыми специалистами (например, за судебным медиком), но в случае экспертизы временной нетрудоспособности (ЭВН) экспертом может быть любой врач. Это один из самых массовых видов экспертиз, используемых для целей государственного управления в России, хотя он куда реже становится предметом изучения, чем, например, медико-социальная экспертиза. Так, согласно данным Минздрава России, в 2014 г. в РФ было зарегистрировано более 25 млн случаев временной нетрудоспособности (ЕМИСС 2017). По информации ФСС, в год в России выдается до 40 млн листков нетрудоспособности (ФСС 2017). В то же время, в 2014 г. освидетельствование в бюро медико-социальной экспертизы прошли 2,78 млн человек (Росстат 2015: 79).

ЭВН призвана подтвердить страховой случай и необходимость выплаты пособия, то есть когда врач отправляет пациента на больничный, он выносит решения, обеспечивающие работу системы государственного социального страхования. От того, как организована и проходит эта экспертиза, зависит решение вопросов, выходящих за пределы медицины, занятости, финансов граждан и государственной помощи им. В 2017 г. Фонд социального страхования РФ отметил 80-летие листка нетрудоспособности, выстраивая таким образом преемственность с советской системой выдачи больничных (ФСС 2017). Однако по сравнению с тем временем подход государства к труду и занятости кардинально изменился. Претерпел ли вслед за этим существенные изменения институт ЭВН? Задача настоящей статьи - сопоставить советское и современное устройство экспертизы временной нетрудоспособности. Исторический ракурс полезен тем, что позволяет анализировать качество экспертизы с учетом особенностей ее становления и предназначения.

Этот тематически узкий сюжет также имеет выход на более общие проблемы исследований российской социальной политики. Одна из них оценка преемственности и рудиментов советского прошлого в этой сфере. В отличие от экономики, ключевые изменения в ней были отложены 
во времени (Григорьева 2007), а формирование действующей нормативной базы и реформы здравоохранения, образования, социального обеспечения пришлись на последнее десятилетие. Насколько эти изменения могут быть безболезненными и эффективными? Другая проблема - текущий статус медицинского профессионала в России, определяющий границы его автономии и власти. За советским врачом закрепилась характеристика «бюрократического профессионала» (Field 1988), состоящего на службе у государства. Советская медицина вообе рассматривалась некоторыми исследователями как депрофессионализированное занятие (Schecter 1992; Haug 1976). И врач воспринимается социологами как винтик государственной машины наряду с полицейскими и чиновниками (Панеях 2013), а сами медики говорят о свободном профессионале лишь как об идеале (Крашенинникова 2014).

Устройство института экспертизы временной нетрудоспособности в настоящей работе рассматривается через три его элемента: господствующее понимание задач экспертизы, особенности организации и регламентации процедур, практики экспертной деятельности. Для этого был проведен сравнительный анализ нормативных актов СССР и РФ, регулирующих ЭВН и выдачу больничных листков, а также содержания советской и современной учебно-методической литературы для врачей. Для понимания советских практик экспертизы использовались архивные материалы ВЦСПС 1930-1980-х гг.: стенограммы совещаний, проекты нормативных актов, докладов и справок, отчеты о результатах проверок. Оценка современных практик основана на анализе 31 полуструктурированного интервью с практикующими врачами (12 чел.), представителями руководства медицинских организаций (14 чел.) - в т. ч. заместителями главврача по клинико-экспертной работе (8 чел.) и контрольных ведомств (5 чел.). При подборе информантов учитывалась вероятность различий в практиках экспертизы, обусловленная размером и статусом медицинских организаций и, соответственно, числом выдаваемых листков нетрудоспособности. Интервью с медиками проводились в крупных многопрофильных центрах, городских поликлиниках, ЦРБ и изолированных сельских подразделениях ЦРБ. География исследования включала пять регионов России, но важно, что исследуемая сфера регулируется федеральными нормативными актами, т.е. в ней действуют единые правила. Интервью имеют среднюю продолжительность 45 минут (в диапазоне от 15 минут до 2 часов) и были получены в декабре 2016 г. - апреле 2017 г.

Исследование имеет ряд ограничений. За его рамками намеренно оставлены смежные направления медицинской экспертной деятельности, используемые для нужд социального обеспечения (медико-социальная экспертиза, экспертиза связи состояния здоровья с профессиональной деятельностью, экспертиза профессиональной пригодности). Также я не касаюсь вопросов изменения прав граждан в системе социального страхования, хотя они оказывали воздействие и на саму экспертизу. Наконец, при сопостав- 
лении советской и современной ситуации не учитывается эволюция социальной политики и системы здравоохранения на протяжении советского периода, которая могла отчасти повлиять на ЭВН несмотря на то, что базовый подход к труду и занятости оставался неизменным.

\section{Задачи экспертизы: подтверждение страхового случая или рациональное распределение трудовых ресурсов}

Хотя экспертиза нетрудоспособности в России появилась еще в начале XX в. с принятием социальных законов о страховании рабочих в 1903 и 1912 гг., становление советской модели можно относить к 1930-м гг. Это произошло в то время, когда социальная политика определялась задачами производственной дисциплины и стимулирования труда (Романов 2003), как и организация здравоохранения (Бартон 2007). Обоснование экспертной деятельности врача в СССР опиралось на нормативное и идеологическое отношение к труду как к «первой жизненной потребности каждого советского человека» (Конституция СССР 1977:Ст. 14). Труд в советском обществе, по выражению Владимира Магуна, имел священный, сакральный смысл, а сама идеология общества была «трудоцентристской» (Магун 1998:2).

Как подчеркивалось в советских учебниках по экспертизе для врачей, именно в отношении к труду принципиальное отличие советской экспертизы от капиталистической. Если предназначение последней сводится лишь к установлению страхового случая и освобождению от труда, то социалистический подход предполагал рациональное трудоустройство в соответствии с возможностями здоровья или «длительное сохранение трудовой деятельности рабочих и служащих» (Гладштейн 1952:218). В одном из руководств для врачей формулировалось так: «Задача экспертизы сводится к сохранению кадров и поднятию производительности труда путем правильной расстановки на производстве рабочих с патологическими нарушениями организма соответственно их состоянию здоровья» (Гладштейн и др. 1935:9). В соответствии с таким подходом врачам-клиницистам, как и врачам-экспертам врачебно-трудовой экспертной комиссии (ВТЭК), предписывалось разбираться в социальных факторах нетрудоспособности: в условиях труда, профессиях и деталях быта пациентов. Например, в письме от 6.11.1951 № 01-23/28 министр здравоохранения СССР обязывал «проводить ознакомление врачей общей сети здравоохранения с промышленными особенностями труда рабочих» на обслуживаемой территории (Берлянд 1961:29). Обязанности лечащего врача расширялись до решения социальных вопросов: «каждый клиницист, наряду с вопросами медицинской диагностики и терапии, должен думать всегда о трудовом прогнозе, а часто и решать вопрос трудоспособности» (Вегер 1970:4).

О разнице советского и западного подхода к выдаче больничных листков писали и зарубежные исследователи советского здравоохранения, 
работавшие в рамках концептуальной дихотомии «демократические vs тоталитарные общества». Они указывали, что если в первом случае «полицейская» роль медика сведена к минимуму благодаря его профессиональной независимости, то во втором он не может отказаться от того, чтобы выполнять функцию укрепления трудовой дисциплины (Ryan, 1980). Как отмечал Марк Филд, «положение советского врача отражает корпоративную слабость профессии и силу клинициста как бюрократического служащего» (Field 1988:200). На чем может быть основано такое разделение? Ведь практика подтверждения врачом факта нетрудоспособности существует во многих странах с развитыми системами общественного здравоохранения, например, в Европе. Однако, как отмечают европейские авторы, там доктор играет роль «привратника» при доступе пациентов к благам социального страхования. Причем делает это неохотно, испытывая внутренний конфликт выбора между ценностями защиты больного и интересами общества (Swartling et al. 2007; Hussey et al. 2004). Он не является распорядителем этих благ, и тем более не обязан выявлять тех, кто отлынивает от работы. Медицинский сертификат лишь выражает мнение доктора о состоянии здоровья пациента, а решение о выплате компенсаций по болезни принимает служащий социального страхования, на практике полагаясь на заключение лечащего врача (Söderberg, Alexanderson 2005). В СССР, как и сегодня в РФ, листок нетрудоспособности являлся документом одновременно медицинским, социальным и финансовым, заполнялся на бланке строгой отчетности и дополнительно служил целям статистического учета и контроля соблюдения режима пациентом.

В постсоветской России, где труд перестал быть обязанностью и стал правом, базовая задача экспертизы временной нетрудоспособности по рациональному распределению трудовых ресурсов в соответствии с состоянием здоровья отпала. Врач, по сути, лишь подтверждает страховой случай, то есть выступает посредником в правовых и финансовых отношениях между пациентом и его работодателем. Причем это посредничество лишено обязательности, поскольку система социального страхования на случай временной нетрудоспособности более не является всеобъемлющей для работающих (из-за малого размера пособия, практик теневого трудоустройства, режима работы и других причин). Хотя больничный лист выписывается по требованию пациента, иногда ему выгоднее «отпроситься на работе на два дня поболеть дома» (терапевт, ок. 30 лет, Москва).

Идеологический поворот находит отражение и в языке нормативных актов. Так, если в Положении об экспертизе временной нетрудоспособности от 14 июля 1975 г. говорилось, что ее задачи состоят в определении утраты трудоспособности и рекомендации соответствующих условий труда (Положение Минздрава СССР 1975:п. I.1), то Положение от 13 января 1995 г. целью экспертизы называло «оценку состояния здоровья пациента, качества и эффективности проводимого обследования и лечения, возможности 
осуществлять профессиональную деятельность, а также определение степени и сроков временной утраты трудоспособности» (Приказ Минздравмедпрома РФ 1995: п. 1.1).

\section{Устройство экспертизы и его влияние на организацию работы медицинской организации}

То, что основной задачей ЭВН в СССР было рациональное трудоустройство, определяло особенности ее институциального дизайна. В комплексе нормативных актов, формирующих этот дизайн, ключевым документом была инструкция ВЦСПС и Наркомздрава СССР «О порядке выдачи застрахованным больничных листков» от 14 августа 1937 г. Показательно, что она с некоторыми изменениями просуществовала до 1994 г. и действующий порядок выдачи листков нетрудоспособности принципиально от нее не отличается. Рассмотрим четыре основных особенности устройства экспертизы и то, сохранились ли они до настоящего времени. Во-первых, экспертиза нетрудоспособности, обеспечивающая как выдачу больничных, так и признание инвалидности, сформировалась и развивалась как единый институт. Экспертная работа в лечебно-профилактическом учреждении (ЛПУ) и в системе ВТЭК рассматривалась как цельный процесс, хотя имела разную ведомственную подчиненность, а определение инвалидности оформилось в отдельную медицинскую специальность. Важность связи двух звеньев экспертизы лейтмотивом проходила в рекомендациях, учебниках и инструкциях для врачей на протяжении десятилетий. Базовая классификация видов нетрудоспособности по двум основаниям (временная/стойкая, частичная/полная) возлагала обязанности оптимального трудоустройства больных не только на ВТЭК, но и на медицинские учреждения, которые в случае частичной временной нетрудоспособности должны были давать больным направления для перевода на более легкую работу и определять наступление стойкой нетрудоспособности. Расхождение в оценке последней между клиницистами и экспертами ВТЭК считалось недочетом, с которым ЛПУ нужно бороться.

В постсоветский период медико-социальная экспертиза не только полностью отделена от экспертизы временной нетрудоспособности - ее предметом не является нетрудоспособность, но потребность в мерах социальной защиты. Однако согласованность мнения поликлиники, направившей пациента на экспертизу, и мнения бюро МСЭ остается предметом контроля со стороны органов управления здравоохранением. По словам информантов, случаи расхождений до сих пор порицаются и разбираются на совещаниях, и ответственным за клинико-экспертную работу присылают сигнальные извещения с требованиями дать объяснения, какие основания для инвалидности они увидели.

Во-вторых, в медицинском учреждении было фактически два уровня ЭВН. На первом уровне лечащий врач единолично определял нетрудоспо- 
собность пациента на определенный срок, который в исторической перспективе увеличивался (с 3 и 6 дней - до 10 и 30 в постсоветское время, затем 15 дней). Если пациент болел дольше этого срока, то продление его больничного согласовывали заведующий отделением, заместитель главврача или, чаще всего, комиссия. Этой комиссии, называвшейся в разное время врачебно-консультационной, врачебно-контрольной, клинико-экспертной, врачебной, в ЛПУ отводилась роль распределителя бюджетных ресурсов, которыми мог воспользоваться пациент в системе социального обеспечения. Помимо подтверждения права на больничный, она направляла на временную работу по состоянию здоровья, на ВТЭК и в санаторно-курортные учреждения.

Это распределение полномочий в части маршрутизации пациентов стало важной частью властной иерархии внутри ЛПУ, которая благополучно перешла в постсоветское здравоохранение. Оно обеспечивает контроль руководства над профессиональными решениями и добросовестностью врачей, а также над использованием ресурсов (например, койко-мест). Сегодня врачебная комиссия согласует вопрос о назначении льготных лекарств и направляет на получение высокотехнологичной медицинской помощи. По выражению одного из информантов, «если смотреть по приказу № 502른 практически ВК - это основной руководящий и направляющий орган лечебного учреждения» (заместитель главврача, ок. 50 лет, районный центр). Двухуровневое устройство экспертизы частично нивелирует экспертный статус отдельного врача. Однако для большинства информантов это не составляло проблемы. Они отмечали, что в идеале, согласовывая продление больничного, комиссия проверяет качество медицинской помощи. Важно и то, что она позволяет доктору снять с себя ответственность в случае конфликта с пациентом: «Одна голова - хорошо, а три лучше. Кроме того, доктор так юридически защчщщен» (врач, ок. 30 лет, региональный центр).

В-третьих, задача минимизации отстранения пациентов от работы определяла сами правила выдачи больничного листка в СССР. В конечном счете они служили достижению целевого показателя временной нетрудоспособности, установленного, как говорилось в постановлении Президиума ВЦСПС от 29 марта 1962 г., «по бюджету государственного социального страхования». Прежде всего, речь идет об упомянутом выше коротком сроке, на который лечащий врач мог единолично выписывать больничный. Это обосновывалось необходимостью «тщательного динамического наблюдения над больным со стороны лечащего врача и заведующего отделением» (Новиков, Савельев 1975:20), хотя на самом деле течение заболеваний различно и во многих случаях за короткий срок серьезных изменений

\footnotetext{
${ }^{1}$ Имеется в виду Приказ Минздравсоцразвития России от 5 мая 2012 г. № 502 н «Об утверждении порядка создания и деятельности врачебной комиссии медицинской организации».
} 
не произойдет. На снижение рисков злоупотреблений со стороны врачей было направлено требование личного осмотра пациента при продлении больничного листка комиссией или заведующим отделением. Кроме того, был ограничен круг лиц и учреждений, имеющих право выдачи больничных. В вину медицинским учреждениям государство ставило и выдачу больничных листков неприкрепленным пациентам, случайно обратившимся за получением консультации врача. Диспансерное наблюдение за длительно и часто болеющими людьми также служило задачам социального страхования. Такие пациенты прикреплялись к одному врачу, и больничные листки, выданные другими врачами, оплачивались только в исключительных случаях. Помимо этого, государство ставило медикам задачу проводить диагностические процедуры и прием трудящихся по возможности в вечерние часы или в выходные дни. Наконец, существовала и поощрялась практика перевода больных с частичной нетрудоспособностью на временную работу.

В постсоветский период большинство этих правил ушли в прошлое, однако некоторые практики сохранились. Например, в сельских ЦРБ до сих пор принято осматривать пациента на врачебной комиссии, хотя нормативно такого требования сейчас нет. Сроки единоличного продления врачом больничного увеличились, однако те изменения, которые происходили, также не были привязаны к специфике лечения, а обуславливались задачами социального страхования (см.: Приказ Минздравмедпрома РФ 1994; Приказ Минздравсоцразвития РФ 2011). Причем в 2000 г. появился другой сдерживающий фактор - ориентировочные сроки временной нетрудоспособности при разных заболеваниях (но без учета профессий/занятий), которые превратились в настольный документ участкового терапевта. А в последние годы вопрос о том, сколько дней можно болеть пациенту, решают медико-экономические стандарты, к определению нетрудоспособности отношения не имеющие.

Четвертый элемент дизайна института: в СССР был детально регламентирован процесс выписки больничных листов, а не сама экспертиза. Такая же ситуация сохранилась и в современной России. Оценка состояния больного, сроки нахождения на больничном, назначение режима - все это относится к сфере исключительной компетенции медицинского профессионала, что соответствует общему смыслу экспертной деятельности. Предписаниям и контролю подлежит правильность хранения и заполнения бланков, а также подробность заполнения карты больного - но не само решение, которое было и остается субъективным.

Это отражается и в понимании ЭВН самими медиками. Из интервью с врачами видно, что для них это - рутинная часть их повседневной работы. Хотя она характеризуется как дополнительная «писанина», все информанты говорили о ней как о непроблемном и необременительном занятии. Не встречались в разговоре и моральные коллизии по поводу оценки трудоспособности, 
о которых пишут европейские исследователи (Swartling et al. 2007; Hussey et al. 2004). На вопрос «каким образом Вы решаете для себя, трудоспособен пациент или нет», каждый врач называл критерии, в основном выработанные интуитивно, исходя из своего опыта, а не являющиеся результатом консенсуса в профессиональной среде или детальных инструкций. В отличие от практикующего врача, для менеджеров медицинских центров, которые являются буфером между экспертом и проверяющими инстанциями, эта сфера полна трудностей и подводных камней. Однако усилия этих информантов связаны главным образом с соблюдением формальных требований внешних контролеров из ФСС и других ведомств, а основной стресс - с изменчивостью и расплывчатостью этих требований, а не с качеством экспертных решений.

\section{Экспертиза на практике: обход правил и внешний контроль}

Несмотря на то, что правила и процедуры ЭВН в советское время были подчинены задаче рационального распределения трудовых ресурсов, учреждения здравоохранения с этой задачей не справлялись. Из текстов методических пособий для врачей, полных должествований и осторожных формулировок текущих недостатков, видно, что экспертиза нетрудоспособности была во многом формальным институтом, и формальным к ней было отношение самих медиков.

Лейтмотивом справок и отчетов ВЦСПС о проверках на протяжении десятилетий проходят одни и те же ошибки и недочеты. Это неправильное заполнение больничных листков, нарушения инструкций в части сроков и категорий больных, факты хищения бланков, «недостаточная деятельность» органов здравоохранения по организации экспертизы и «слабая осведомленность» врачей. Так, в 1947 г. сообщалось о «слабой постановке экспертизы трудоспособности и незнании лечащими врачами законодательства по социальному страхованию» (ГАРФ. Ф. 5451. О.29. Д.229. Л. 10); в 1980 - о том, что «повсеместно продолжают иметь место нарушения действующего законодательства по выдаче больничных листков» (ГАРФ. Ф. 5451. Оп.29. Д.1835. Л. 5).

Комиссии также не справлялись со своей задачей внутреннего контроля над ЭВН. «Врачебно-консультационные комиссии в ряде учреждений существуют только формально, и вся их работа сводится к механическому штампованию продления больничных листков, причем нередко это делается без осмотра больного, заочно и необоснованно» - сообщалось на заседании президиума ВЦСПС в 1949 г. (ГАРФ. Ф. 5451. Оп.29. Д.375. Л. 96). Они работают формально, существуя в основном на бумаге,- читаем мы и в статье представителя руководства Росздравнадзора России от 2010 г. (Тельнова 2010). Аналогичные оценки даются и в интервью: 
С учетом того объема, который на них ложится, ведь у нас действительно колоссальное число случаев выносится на ВК, <..>, конечно, сейчас это вещь очень формальная (чиновник, ок. 40 лет, региональный центр).

В условиях слабого контроля внутри медицинских учреждений развивались формы внешнего, вневедомственного контроля экспертизы. В советское время помимо ВТЭК это были общественные советы при медицинских учреждениях, комиссии социального страхования, советы по социальному страхованию на предприятиях, страховые врачи и страховой актив. Сегодня функцию внешнего контроля выполняет в первую очередь ФСС. Примечательно, что из-за перипетий распределения полномочий между ведомствами специалисты фонда могут законно проверять только порядок выдачи листков нетрудоспособности, но не саму экспертизу. Как и в других вопросах медицинской деятельности, предметом проверок здесь является бюрократическое оформление деятельности, но не сама деятельность. В конечном счете работа контролеров сводится к изучению журналов, протоколов врачебной комиссии и записей в медицинской карте, которые могут быть отличны от реального положения дел. Как указывали информанты, если врач грамотно заполнил карту, то выявить факт выдачи листка нетрудоспособности здоровому человеку практически невозможно: «Понимаете, если доктор захотел выдать липовый больничный лист, он так его обставит, что когда мы почитаем, мы просто заплачем от жалости к этому пациенту» (заместитель главврача, ок. 60 лет, районный центр).

\section{Заключение}

Специфику советского института ЭВН определяла возложенная на нее миссия рационального распределения трудовых ресурсов для их оптимального использования в экономике страны. В современной России, где труд перестал быть обязанностью каждого гражданина, задача ЭВН сводится к подтверждению страхового случая, обеспечению государственного социального страхования экспертным мнением о состоянии здоровья пациента.

Анализ показывает, что ЭВН в СССР воспринималась как этап врачебно-трудовой экспертизы, и внутри медицинского учреждения была как минимум двухуровневой. Выдача больничного листка была организована так, чтобы контролировать действия лечащего врача и минимизировать отстранения пациентов от работы. При этом был регламентирован процесс выписки листков, но не сама экспертиза. Эти характеристики (этапность экспертизы, распределение полномочий внутри медицинского учреждения, перекосы регламентации) в значительной степени сохранились до наших дней, причем некоторые процедуры поддерживаются на местах, хотя не предписаны в нормативных актах.

Представляется, что случай ЭВН иллюстрирует общий парадокс врачебной профессии в СССР, о котором упоминалось во введении. Государство 
предоставляло медикам дополнительные полномочия и обязанности, выходящие за рамки собственно клинической работы, причем не только в части распределения социальных благ, как в других обществах с социальным страхованием, но и принуждения к труду. Но при этом оно оспаривало авторитет и компетенции эксперта, вводя дополнительные меры контроля над его деятельностью, поскольку с поставленной задачей экспертизы медицинские учреждения не справлялись, воспринимая ее процедуры и правила формально.

В целом, в процедурах и практиках современной ЭВН многое сохранилось от советской модели, хотя миссия поменялась кардинально. Установленные когда-то правила продолжают влиять на организацию профессиональной врачебной деятельности и лечебного процесса, определяя рутину взаимодействия медицинского учреждения с пациентом. Как резюмировала одна из информанток, проработавшая в здравоохранении около 40 лет, «собственно, сильно-то ничего и не изменялось, кроме образцов больничного листа» (заместитель главврача, ок. 70 лет, региональный центр).

\section{Список сокращений}

ВЦСПС - Всесоюзный центральный совет профессиональных союзов

ГАРФ - Государственный архив Российской Федерации

ЦРБ - центральная районная больница

\section{Выражения признательности}

Статья подготовлена в рамках исследовательского проекта «Практики экспертизы в российском государственном управлении» (2016-2018 гг.), финансируемого Фондом поддержки социальных исследований «Хамовники».

\section{Список источников}

Бартон К. (2007) Здравоохранение в период позднего сталинизма и дух послевоенного государства благоденствия, 1945-1953 годы. Журнал исследований соџиальной политики, (4): 541-558.

Берлянд А.С. (1961) Экспертиза временной нетрудоспособности. Изд. 2-е, М.: Медгиз.

Вегер А. М. (1970) Справочник врача по вопросам экспертизы трудоспособности (Общие основы определения стойкой и временной нетрудоспособности). Изд. 2-е, Киев: ЗДОРОВ'Я.

Гладштейн Р.М. (1952) Врачебная экспертиза трудоспособности, М.: Медгиз. 
Гладштейн Р.М., Кончаловский М.П., Руфанов И.Г. (ред.) (1935) Врачебная экспертиза трудоспособности. Руководство для студентов и врачей, М.: НИИ экспертизы трудоспособности ВЦСПС.

Григорьева И.А. (2007) Российская социальная политика в последние годы: между уже пройденным путем и все еще неопределенным будущим. Журнал исследований сочииальной политики, 5 (1): 7-24.

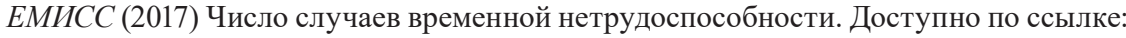
https://fedstat.ru/indicator/41689 (дата обращения: 20 октября 2017).

Конституиия СССР (1977) Принята на внеочередной седьмой сессии Верховного Совета СССР девятого созыва 07.10.1977.

Крашенинникова Ю.А. (2014) Самоопределение и социальный статус российских врачей. Е.Г. Ясин (ред.) XIV Апрельская международная научная конферениия по проблемам развития экономики и общества: в 4-х книгах. Кн. 3, М.: Издательский дом НИУ ВШЭ: 690-697.

Магун В.С. (1998) Российские трудовые ценности: идеология и массовое сознание. Мир России, (4): 113-144.

Новиков А.А., Савельев И.А. (1975) Учебное пособие по врачебно-трудовой экспертизе, М.: Медицина.

Панеях Э. (2013) Зарегулированное государство. Pro et Contra, (январь-апрель): 79-92.

Положение Минздрава СССР (1975) Об экспертизе временной нетрудоспособности в лечебно-профилактических учреждениях (в том числе в клиниках высших медицинских учебных заведений, институтов усовершенствования врачей и научноисследовательских институтов) № 06-14/6 от 14.07.1975.

Постановление Президиума ВЦСПС (1962) О работе медицинских учреждений по организачии экспертизы временной нетрудоспособности и выдачи больничных листков рабочим и служащиим, Протокол № 9, п. 3 от 29.03.1962.

Постановление СНК СССР (1937) О порядке выдачи застрахованным больничных листков № 1382 от 14.08.1937.

Приказ Минздравмедпрома РФ (1994) Инструкция о порядке выдачи документов, удостоверяющих временную нетрудоспособность граждан № 206 от 19.10.1994.

Приказ Минздравмедпрома РФ (1995) О мерах по совершенствованию экспертизы временной нетрудоспособности № 5 от 13.01.1995.

Приказ Минздравсоцразвития РФ (2011) Об утверждении порядка выдачи листков нетрудоспособности № 624н от 29.06.2011.

Приказ Минздравсоцразвития РФ (2012) Об утверждении порядка создания и деятельности врачебной комиссии медицинской организации № 502 н от 05.05.2012.

Романов П.В. (2003) Социальные изменения и социальная политика. Журнал исследований социальной политики, (1): 45-67. 
Росстат (2015) Здравоохранение в России. Статистический сборник, М.: Росстат.

Тельнова Е.А. (2010) Качество оказания медицинской помощи как основная задача системы здравоохранения. Вестник Росздравнадзора, (5): 4-9.

ФСС (2017) Сегодня исполняется 80 лет листку нетрудоспособности. Доступно по ссылке: http://fss.ru/ru/news/232447/256196.shtml (дата обращения: 20 сентября 2017).

Field M. (1988) The Position of the Soviet Physician: The Bureaucratic Professional. The Milbank Quarterly, (66): 182-201.

Haug M.R. (1976) The Erosion of Professional Authority: A Cross-Cultural Inquiry in the Case of the Physician. The Milbank Quarterly, 54 (1): 83-106.

Hussey S., Hoddinott P., Wilson Ph., Dowell J., Barbour R. (2004) Sickness certification system in the United Kingdom: qualitative study of views of general practitioners in Scotland. British Medical Journal, (328): 88-91.

Ryan M. (1980) Questions of sickness certification. British Medical Journal, (281): 791-793.

Schecter K. (1992) Soviet Socialized Medicine and the Right to Health Care in a Changing Soviet Union. Human Rights Quarterly, 14 (2):206-215.

Söderberg E., Alexanderson K. (2005) Gatekeepers in sickness insurance: a systematic review of the literature on practices of social insurance officers. Health \& Social Care in the Community, (13): 211-223.

Swartling M., Peterson S., Wahlström R. (2007) Views on sick-listing practice among Swedish General Practitioners - a phenomenographic study. BMC Family Practice, (78): 44. 
Yulia Krasheninnikova

\title{
TEMPORARY DISABILITY EXAMINATIONS IN THE USSR AND POST-SOVIET RUSSIA: DOCTORS IN THE SERVICE OF THE STATE IN THE MANAGEMENT OF LABOR RESOURCES
}

\begin{abstract}
The paper deals with the Soviet model and modern organisation of temporary disability examinations, which is one of the most common types of expert assessment within public administration in Russia. A comparative historical approach is used. Three aspects of these examinations are in focus: ideology or the dominant understanding of its tasks and the 'mission'; the characteristics of the organisation and regulation of procedures; the practices behind these examinations. The key question is whether this institution, which was established in Soviet times, has undergone modifications given the dramatic changes in the state's attitude to work and employment since the fall of the USSR. A comparative analysis of the regulations of the USSR and the Russian Federation is provided, as well as an analysis of the content of Soviet and contemporary educational literature for physicians. To determine how sick leave provision was organised in practice in the Soviet era, the archival documents of All-Union Central Soviet of Trade Unions over the period 1930-1980 (transcripts of meetings, reports on results of inspections etc.) were examined. Evaluation of modern practices of the examination is based on thirty-one semi-structured interviews with physicians and the representatives of medical centres management and monitoring bodies. Rather than operating as an means of social protection of the citizens, it makes more sense to view the Soviet-era institution of temporary disability examinations as a tool aiming at the rational distribution of labour resources for optimal use in the national economy. Medical providers could not cope with this task of examination and regarded its procedures and rules formally. However, these procedures and rules have influenced and continue to influence the organisation of professional medical practice and therapeutic process, defining routine interactions between medical institutions and patients.
\end{abstract}

Keywords: temporary disability examination, Soviet healthcare, medical commission, medical-labour examination, public social insurance, sick leave, sickness certificate

DOI: 10.17323/727-0634-2017-15-4-531-546

\section{References}

Barton K. (2007) Zdravookhranenie v period pozdnego stalinizma i dukh poslevoennogo gosudarstva blagodenstviya, 1945-1953 gody [Universality Under Stalinism? Late Stalinist Healthcare and the Ghost of the Postwar Welfare State, 1945-1953]. Zhurnal issledovaniy sotsial'noy politiki [The Journal of Social Policy Studies], 5 (4): 541-558.

Yulia Krasheninnikova - PhD (Kandidat Nauk) in History, Expert at the Laboratory for Local Administration of the National Research University Higher School of Economics in Moscow, Associate Professor at the School of Management of the HSE Campus in Perm, Russian Federation. Email: jkrasheninnikova@hse.ru 
Berlyand A. S. (1961) Ekspertiza vremennoy netrudosposobnosti [The Temporary Disability Examination], Moscow: Medgiz.

EMISS (2017) Chislo sluchaev vremennoy netrudosposobnosti [The Number of Temporary Disability Cases]. Available at: https://fedstat.ru/indicator/41689 (accessed 20 October 2017).

Field M. (1988) The Position of the Soviet Physician: The Bureaucratic Professional. The Milbank Quarterly, (66): 182-201.

FSS (2017) Segodnja ispolnjaetsja 80 let listku netrudosposobnosti [Sick Leave Turns eighty today]. Available at: http://fss.ru/ru/news/232447/256196.shtml (accessed 20 September 2017).

Gladshteyn R. M. (1952) Vrachebnaya ekspertiza trudosposobnosti [Medical Examinations of work capacity], Moscow: Medgiz.

Gladshteyn R.M., KonchalovskiyM.P., Rufanov I. G. (eds.) (1935) Vrachebnaya ekspertiza trudosposobnosti [Medical examinations of work capacity], Moscow: NII ekspertizy trudosposobnosti VtsSPS.

Grigor'eva I.A. (2007) Rossiyskaya sotsial'naya politika v poslednie gody: mezhdu uzhe proydennym putem i vse eshche neopredelennym budushchim [Russian Social Policy in the Recent Years: Between the Way Already Passed and Yet Uncertain Future]. Zhurnal issledovaniy sotsial'noy politiki [The Journal of Social Policy Studies], 5 (1): 7-24.

Haug M.R. (1976) The Erosion of Professional Authority: A Cross-Cultural Inquiry in the Case of the Physician. The Milbank Quarterly, 54 (1): 83-106.

Hussey S., Hoddinott P., Wilson Ph., Dowell J., Barbour R. (2004) Sickness Certification System in the United Kingdom: Qualitative Study of Views of General Practitioners in Scotland. British Medical Journal, (328): 88-91.

Konstitutsiya SSSR (1977) [The Constitution of the USSR] Prinyata na vneocherednoy sed'moy sessii Verkhovnogo Soveta SSSR devyatogo sozyva 07.10.1977.

Krasheninnikova Yu.A. (2014) Samoopredelenie i sotsial'nyy status rossiyskikh vrachey [SelfIdentification and Social Status of Russian Physicians]. E. G. Yasin (ed.) XIV Aprel'skaya mezhdunarodnaya nauchnaya konferentsiya po problemam razvitiya ekonomiki i obshchestva: $v$ 4-kh knigakh [XIV April International Academic Conference On Economic and Social Development Proceedings: in 4 books], Vol. 3, Moscow: HSE-Press: 690-697.

Magun V. S. (1998) Rossiyskie trudovye tsennosti: ideologiya i massovoe soznanie [Russian Labor Values: Ideology and Mass Consciousness]. Mir Rossii [Universe of Russia], 7 (4): 113-144.

Novikov A.A., Savel'ev I.A. (1975) Uchebnoe posobie po vrachebno-trudovoy ekspertize [Manual for Medical-Labor Examinations], Moscow: Meditsina.

Paneyakh E. (2013) Zaregulirovannoe gosudarstvo [The Overregulated State]. Pro et Contra, (1):79-92.

Polozhenie Minzdrava SSSR (1975) Ob ekspertize vremennoy netrudosposobnosti v lechebno-profilakticheskikh uchrezhdeniyakh [On the Temporary Disability Examination in Medical Organizations] № 06-14/6 from 14.07.1975. 
Postanovlenie Prezidiuma VTsSPS (1962) O rabote meditsinskikh uchrezhdeniy po organizatsii ekspertizy vremennoy netrudosposobnosti $i$ vydachi bol'nichnykh listkov rabochim $i$ sluzhashchim [On the Work of Medical Institutions in Organizing Temporary Disability Examinations and Medical Certificates Provision for Workers and Employees]. Protocol 9, p. 3 from 29.03.1962.

Postanovlenie SNK SSSR (1937) O poryadke vydachi zastrakhovannym bol'nichnykh listkov [On the Procedure for the Issuance of Medical Certificates Provision to the Insured] № 1382 from 14.08.1937.

Prikaz Minzdravmedproma RF (1994) O poryadke vydachi dokumentov, udostoveryayushchikh vremennuyu netrudosposobnost' grazhdan [On the Procedure for the Provision of Documents Certifying Temporary Disability of Citizens] № 206 from 19.10.1994.

Prikaz Minzdravmedproma RF (1995) O merakh po sovershenstvovaniyu ekspertizy vremennoy netrudosposobnosti [On the Measures to Improve the Temporary Disability Examinations] № 5 ot 13.01.1995.

Prikaz Minzdravsotsrazvitiya RF (2011) Ob utverzhdenii poryadka vydachi listkov netrudosposobnosti [On Approval of the Procedure of Medical Certificates Provision] № 624n from 29.06.2011.

Prikaz Minzdravsotsrazvitiya RF (2012) Ob utverzhdenii poryadka sozdaniya i deyatel'nosti vrachebnoy komissii meditsinskoy organizatsii [On Approval of the Procedure of Creation and Activity of the Medical Commission of the Medical Organization] № 502n from 05.05.2012.

Romanov P. V. (2003) Sotsial'nye izmeneniya i sotsial'naya politika [Social Changes and Social Policy]. Zhurnal issledovaniy sotsial'noy politiki [The Journal of Social Policy Studies], 1 (1): 45-67.

Ryan M. (1980) Questions of Sickness Certification. British Medical Journal, (281): 791-793.

Schecter K. (1992) Soviet Socialized Medicine and the Right to Health Care in a Changing Soviet Union. Human Rights Quarterly, 14 (2): 206-215.

Söderberg E., Alexanderson K. (2005) Gatekeepers in Sickness Insurance: A Systematic Review of the Literature on Practices of Social Insurance Officers. Health \& Social Care in the Community, (13):211-223.

Swartling M., Peterson S., Wahlström R. (2007) Views on Sick-listing Practice among Swedish General Practitioners: A Phenomenographic Study. BMC Family Practice, 78: 44.

Tel'nova E. A. (2010) Kachestvo okazaniya meditsinskoy pomoshchi kak osnovnaya zadacha sistemy zdravookhraneniya [Quality of Medical Care as the Main Goal of the Healthcare System]. Vestnik Roszdravnadzora [Roszdravnadzor's Bulletin], (5): 4-9.

Veger A. M. (1970) Spravochnik vracha po voprosam ekspertizy trudosposobnosti (Obshchie osnovy opredeleniya stoykoy i vremennoy netrudosposobnosti) [A doctor's guide to work capacity examinations], Kyiv: ZDOROV'Ya.

Rosstat (2015) Zdravookhranenie v Rossii. Statisticheskij sbornik [Healthcare in Russia. A statistical handbook], Moscow: Rosstat. 